\title{
The effectiveness of surgical correction of uterine prolapse: cervical amputation with uterosacral ligament plication (modified Manchester) versus vaginal hysterectomy with high uterosacral ligament plication
}

\author{
Tiny A. de Boer • Alfredo L. Milani • \\ Kirsten B. Kluivers • Mariella I. J. Withagen • \\ Mark E. Vierhout
}

Received: 6 March 2009 / Accepted: 9 June 2009/Published online: 11 August 2009

(C) The Author(s) 2009. This article is published with open access at Springerlink.com

\begin{abstract}
Introduction and hypothesis The objective of this study is to evaluate cervical amputation with uterosacral ligament plication (modified Manchester) and compare it to vaginal hysterectomy with high uterosacral ligament plication procedure with special regard to the middle compartment. Methods Consecutive women with pelvic organ prolapse who underwent either vaginal hysterectomy or a modified Manchester procedure were included. Assessments were made preoperatively and at 1-year follow-up, including physical examination with pelvic organ prolapse quantification standardised questionnaires (incontinence impact questionnaire, urogenital distress inventory, and defaecatory distress inventory).

Results Between 2002 and 2007, 156 patients were included. Ninety-eight patients returned for a 1-year follow-up. In the modified Manchester group, we found no middle compartment recurrence versus two (4\%) in the vaginal hysterectomy group. Anterior and posterior compartment prolapse recurrences (stage $\geq 2$ ) were similar (approximately 50\%). Considering operating time and blood loss, modified Manchester was more favourable. There was no difference in the pre- and postoperative
\end{abstract}

T. A. de Boer $(\bowtie) \cdot$ K. B. Kluivers $\cdot$ M. I. J. Withagen

M. E. Vierhout

Department of Obstetrics and Gynaecology,

Radboud University Nijmegen Medical Centre,

P. O. Box 9101, 6500 HB Nijmegen, The Netherlands

e-mail: T.deBoer@obgyn.umcn.nl

\section{A. L. Milani}

Department of Obstetrics and Gynaecology,

Reinier de Graaf Group,

Delft, The Netherlands subjective scores. The overall functional outcome was acceptable.

Conclusions We found an excellent performance of both procedures regarding middle compartment recurrences.

Keywords Cervical amputation · Hysterectomy ·

Manchester Pelvic organ prolapse $\cdot$ POP-Q .

Uterosacral ligament

$\begin{array}{ll}\text { Abbreviations } \\ \text { DDI } & \text { Defaecatory distress inventory } \\ \text { IIQ } & \text { Incontinence impact questionnaire } \\ \text { POP } & \text { Pelvic organ prolapse } \\ \text { POP-Q } & \text { Pelvic organ prolapse quantification } \\ \text { UDI } & \text { Urogenital distress inventory }\end{array}$

\section{Introduction}

Pelvic floor dysfunction is a major health issue in elderly women. Prevalence rates of pelvic organ prolapse (POP) increase with age. The lifetime risk of undergoing at least one operation for prolapse or incontinence by the age of 80 years is $11 \%$. One third of all operated women will undergo repeat surgery for recurrent prolapse [1].

Whether or not to preserve the prolapsed uterus is still a matter of debate [2-4]. Furthermore, in recent years, more emphasis on the uterosacral ligaments as the most prominent structures to prevent uterine or middle compartment descensus has emerged [5]. Therefore, it appeared logical to use techniques that incorporate these ligaments in the restoration of the middle compartment. Cervical amputation 
is part of the classical Manchester procedure, a surgical procedure for the correction of a prolapsed uterus. In this classical procedure, the cardinal ligaments are transposed from its lateral position to an anterior position [6-8].

In the last decennium, we have modified the Manchester procedure in such a way that more benefit is achieved from the uterosacral ligaments. In the present study, we have evaluated this modified Manchester procedure with uterine preservation in comparison to vaginal hysterectomy with high uterosacral plication with special regard to the middle compartment.

\section{Materials and methods}

Procedures

\section{Cervical amputation with uterosacral ligament plication}

In case of concomitant anterior colporrhaphy, this procedure is performed first. The colporrhaphy is started with hydrodissection with 20-30 cc of normal saline followed by a vaginal midline incision from the urethrovesical junction until the fold of the bladder at the cervix. The cervix is circumcised. The bladder is then dissected from the cervix over $2-3 \mathrm{~cm}$. The peritoneal cavity is not opened. The dissection of the bladder from the vagina is performed sharply with either scissors or knife. The bladder is subsequently plicated with a number, usually five or six, interrupted sutures Vicryl 2-0. In order to prevent an anterior enterocele, the most proximal plicating suture incorporates the cervix cranial to the level of subsequent cervical amputation. After removal of excessive vaginal epithelium, the vagina is closed with a continuous non-locking Vicryl 2-0 stitch. In case the procedure is not combined with an anterior colporrhaphy, the cervix is simply circumcised, and the bladder is dissected from the cervix over 2 to $3 \mathrm{~cm}$.

The next step is to identify the uterosacral ligaments by palpating them at the lateral posterior side of the cervix. The uterosacral ligaments are marked with an Allis clamp on both sides. The cervix is now amputated over 1 to $2.5 \mathrm{~cm}$ depending on the amount of cervical elongation. The vaginal epithelium of the cervix is dissected from the cervix over $0.5 \mathrm{~cm}$ in order to get a better application of the epithelium to the amputated cervix after suturing. Haemostasis of the cervix and vaginal wall is achieved by cauterization.

Plication of the uterosacral ligaments is now performed by a deep Sturmdorf Vicryl 1 suture. This suture was originally used to re-epithelialise the cervix after a conisation. We modified it in such a way that the uterosacral ligaments are incorporated (Fig. 1). It starts with a deep bite at the left, still clamped, uterosacral ligament, running to or close to the cervical ostium. The vaginal epithelium of the posterior vaginal wall is grasped in the same stitch in the
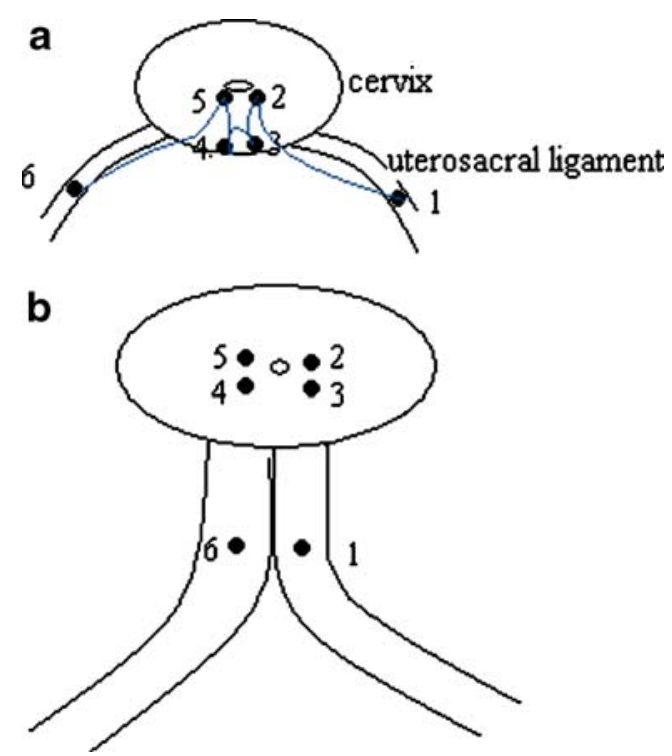

Fig. 1 a Schematic diagram to illustrate the modified Sturmdorf suture on the posterior side after the amputation of the cervix. The suture starts at the left uterosacral ligament about $11 / 2 \mathrm{~cm}$ from the amputated cervix (1). With a deep bite through the cervix, it comes out close to the cervical canal (2). It then takes a superficial double bite through the posterior vaginal wall (3 and 4), after which, another deep bite through the cervix starting in or close to the cervical canal (5) comes out in the right uterosacral ligament around $11 / 2 \mathrm{~cm}$ from the amputated cervix (6). b After tying this suture, the two uterosacral ligaments $(1$ and 6$)$ are united in the midline. There now is a double layer of epithelium between the ligaments. This technique shortens the uterosacral ligaments and thus elevates the uterus. It also partially closes the pouch of Douglas and, thus, has a preventive effect on the development of an enterocele. Posteriorly, the raw amputated surface of the cervix is now covered with vaginal epithelium (3 and 4)

midline in one or two bites, and on the patient's right side, the same deep stitch runs from the cervical ostium through the clamped uterosacral ligament on the right side. Before tying this suture, the anterior side of the cervix is reepithelialised with either a very superficial Sturmdorf suture or simple interruptured Vicryl 2-0 sutures. In contrast with the original Manchester procedure, the ligaments are not cut and transposed but they are transposed merely by plication with the Sturmdorf stitch.

Knot tying of the deep posterior Sturmdorf suture on the posterior side of the cervix now elevates the cervix, because it shortens the uterosacral ligaments and prevents the development of a posterior enterocele. After this procedure, it is checked that the cervical canal is still open and easily accessible. Posterior colporrhaphy is then performed with use of midline fascial plication if deemed necessary.

\section{Vaginal hysterectomy with high uterosacral ligament plication}

In case of additional anterior colporrhaphy, this procedure is performed before or after the vaginal hysterectomy at the 
discretion of the surgeon. The cervix is grasped with a tenaculum forceps and circumcised. The bladder is dissected, and the anterior peritoneum is opened. Posteriorly, a similar procedure is performed, and the pouch of Douglas is opened. Now, the uterosacral ligaments are palpated and grasped with a forceps and cut and ligated with a Vicryl 2-0 suture which is left long. The uterus is removed in several steps with clamps and ligatures of Vicryl 1. After removal of the uterus, the adnexa are inspected. The patient is placed in deep Trendelenburg position. A wetted gauze with a securing suture is introduced in the peritoneal cavity, and a high purse string suture monocryl 0 is started on the left side with a deep bite through the uterosacral ligaments usually about 2 to $3 \mathrm{~cm}$ proximally from the previous attachment to the cervix and close to the level of the ischial spine. Identification of the uterosacral ligaments is facilitated by firm traction on the sutures through the ligament which had been left long. Care is taken to avoid the ureters. The purse string is now proceeding clockwise to the middle of the posterior vaginal wall which is taken in full thickness. Thus, this monocryl suture runs through the peritoneum into the vaginal cavity and back into the peritoneal cavity. The purse string is continued with a similar deep bite on the uterosacral ligament on the right side and, anteriorly, only superficial peritoneum of the vesicouterine fold is incorporated. With the closure of this purse string suture, the posterior vaginal wall is elevated to the level of the deep bites in the uterosacral ligaments. Adaptation of the vaginal epithelium is performed with Vicryl 2-0 interrupted sutures.

Posterior colporrhaphy is performed if deemed necessary with use of midline fascial plication. Our group has a very restrictive policy for concomitant anti-incontinence surgery, and these combined operations were not present in this case series. In both operations, a vaginal pack (for 12-24 h) and a catheter (for 24-48 h) are inserted after the procedure. The procedures are performed under antibiotic prophylaxis coverage with metronidazole, and cefazolin cystoscopy was not performed.

\section{Patients}

The study groups consist of consecutive women who underwent either vaginal hysterectomy with high uterosacral ligament plication or cervical amputation with uterosacral plication in the years 2002-2007 in three large teaching hospitals in The Netherlands (Radboud University Nijmegen Medical Centre, Erasmus University Medical Centre, and Reinier de Graaf Group Delft). The choice for the type of surgery was made in mutual agreement between physician and patient. All women underwent preoperative cytology of the cervix and ultrasound screening of the uterus and adnexa to exclude abnormalities. All women underwent a full gynaecological examination including the pelvic organ prolapse quantification (POP-Q) score [9] and were invited for a postoperative visit 1-year after the operation in which the POP-Q score was repeated. For the compartmental POP-Q stages, the points Ba (anterior), C (middle), and $\mathrm{Bp}$ (posterior) were used in the study. The overall staging was assigned by the leading compartment.

Patient characteristics and perioperative complications were collected from the medical files. Procedures were performed or supervised by senior (uro)gynaecologists. The choice for either procedure was left to the surgeon's discretion. All data are part of a registration project, which was formally deemed exempt from CME/IRB approval.

\section{Measurements}

The patient self-reported questionnaire is a composite of internationally well-known questionnaires that have been validated for the Dutch language. It contains diseasespecific questions from the validated Dutch translation of the incontinence impact questionnaire (IIQ) [10], urogenital distress inventory (UDI) [10], and the defaecatory distress inventory (DDI) [11]. Patients rate the amount of bother of various symptom on a 5-point Likert scale, from 0 (no complaints at all) to 4 (very serious complaints). Scores on various domains are composed [12] on the basis of their Likert scale values on a scale ranging from 0 (best quality of life) and 100 (worst quality of life).

Data are presented as number of women (percentage), mean (standard deviation), or median (range) as appropriate. To compare the difference between groups, the independent samples Student's $t$ test was used in case of normally distributed numerical values, Mann-Whitney in case of not normally distributed numerical values, and chisquare in case of two by two tables. The level of significance was set at alpha of 0.05 . All data were entered and analysed in a Statistical Package for the Social Sciences 15.0 database for Windows (SPSS, Inc., Chicago, IL, USA).

\section{Results}

Table 1 shows the characteristics of the 156 women. No baseline differences between the two groups were found.

In Table 2, an overview of the concomitant operations and complications is presented. The vast majority of women underwent additional anterior and/or posterior repair. Operating time and intraoperative blood loss were more favourable in the cervical amputation group; hospitalisation time, however, was shorter in the vaginal hysterectomy group. Table 3 compares the nine points and distances from the POP-Q before and after surgery. Table 4 gives the overall and compartmental pre- and postoperative POP-Q stages. Table 5 presented the preoperative and postoperative out- 
Table 1 Baseline patient's characteristics

Data are presented as number of women (percentage), mean (SD), or median (range)

$P p$ value using chi-square test, Mann-Whitney, or $t$ test as appropriate

${ }^{\mathrm{a}}$ Median (range)

${ }^{\mathrm{b}}$ Mean (SD)

${ }^{\mathrm{c}}$ Note that data on one vaginal hysterectomy patient is missing

${ }^{\mathrm{d}}$ Note that data on six cervical amputation patients are missing

\begin{tabular}{lccc}
\hline & Cervical amputation $(n=81)$ & Vaginal hysterectomy $(n=75)$ & $P$ \\
\hline${\text { Age }(\text { years })^{\mathrm{a}}}$ & $58(34,83)$ & $57(34,87)$ & 0.542 \\
Parity $^{\mathrm{a}}$ & $2(0,10)$ & $2(1,8)$ & 0.476 \\
${\text { Body Mass Index }(\mathrm{kg} / \mathrm{m} 2)^{\mathrm{a}}}^{\mathrm{a}}$ & $24(19,41)$ & $25(19,31)$ & 0.966 \\
Postmenopausal status & $44(55)$ & $38(51)$ & 0.552 \\
Hormonal replacement therapy $^{\mathrm{b}}$ & $5(6)$ & $3(4)$ & \\
Previous urogynaecological surgery $^{\mathrm{c}}$ & & \\
Anterior compartment & $5(6)$ & $5(7)$ & 0.882 \\
Posterior compartment & $6(7)$ & $6(8)$ & 0.870 \\
Middle compartment & $2(3)$ & $1(2)$ & 0.614 \\
Incontinence surgery $_{\text {Comorbidity }}^{\mathrm{d}}$ & $5(6)$ & $5(7)$ & 0.917 \\
Central nervous system disease & $7(9)$ & & \\
Cardiovascular disease & $16(21)$ & $6(8)$ & 0.772 \\
Respiratory disease & $4(5)$ & $9(12)$ & 0.844 \\
Gastrointestinal disease & $10(13)$ & $11(15)$ & 0.147 \\
Endocrine disease & $3(4)$ & $3(4)$ & 0.814 \\
Musculoskeletal disease & $11(15)$ & $11(15)$ & 1.000 \\
\hline
\end{tabular}

comes and the change as mean of the individual score per patient (preoperative score minus postoperative score) in the various domains from the UDI, IIQ, and DDI. There were no statistically significant differences for any comparison between the two groups of patients.

\section{Discussion}

We have compared the modified Manchester procedure with uterine preservation with vaginal hysterectomy with high uterosacral plication with special regard to the middle compartment. Our study is retrospective, and our data show a selection bias with the vaginal hysterectomy group having a greater degree of preoperative prolapse of the middle compartment than the modified Manchester group. We did not obtain follow-up data for a third of our patients. Given these limitations, both procedures performed excellently with no middle compartment recurrences in the modified Manchester group and 4\% of recurrences in the hysterectomy group. In our hands, the Manchester procedure performed better as compared with the results from earlier studies $[13,14]$; whereas, the results from vaginal hysterectomy were comparable $[15,16]$.

The low number of middle compartment recurrences is in contrast with the high anterior compartment recurrence rate in both groups which was approximately $50 \%$, where recurrency is defined as stage 2 or more independent if there was an operation performed in the compartment. The vulnerability of the anterior compartment for recurrence is however well
Table 2 Concomitant operations intra- and postoperative details

Data are presented as number of women (percentage) or mean (SD). Note: urinary retention was resolved with prolonged catheterisation or intermittent self-catheterisation, there were no long-term consequences; the patient with the bleeding received two packed cells and left the hospital in good condition

$P p$ value using chi-square test or $t$ test as appropriate

${ }^{\mathrm{a}}$ Mean (SD)

\begin{tabular}{|c|c|c|c|}
\hline & Cervical amputation $(n=81)$ & Vaginal hysterectomy $(n=75)$ & $P$ \\
\hline \multicolumn{4}{|l|}{ Concomitant operation } \\
\hline Anterior colporrhaphy & $63(85)$ & $58(92)$ & 0.161 \\
\hline Posterior colporrhaphy & $54(73)$ & $47(75)$ & 0.493 \\
\hline Perineoplasty & $18(32)$ & $16(26)$ & 0.308 \\
\hline \multicolumn{4}{|l|}{ Intraoperative $^{a}$} \\
\hline Operation time (min) & $78(28)$ & $110(35)$ & 0.000 \\
\hline Intraoperative bloodloss (ml) & $191(116)$ & $251(149)$ & 0.006 \\
\hline \multicolumn{4}{|l|}{ Postoperative $^{\mathrm{a}}$} \\
\hline Catheterization (days) & $3.7(4)$ & $3.1(2)$ & 0.198 \\
\hline Length of hospitalisation (days) & $6.1(3)$ & $5.2(2)$ & 0.018 \\
\hline \multicolumn{4}{|l|}{ Complications during hospital stay } \\
\hline Urinary retention & $9(11)$ & $12(16)$ & 0.277 \\
\hline Bleeding & 0 & $1(1)$ & 0.487 \\
\hline
\end{tabular}


Table 3 The nine points and distances from the pre- and postoperative pelvic organ prolapse quantification scores

\begin{tabular}{|c|c|c|c|c|c|c|}
\hline & \multicolumn{2}{|l|}{ Preoperative values } & \multirow[t]{2}{*}{$P$} & \multicolumn{2}{|c|}{ Postoperative values (1year) } & \multirow[t]{2}{*}{$P$} \\
\hline & $\begin{array}{l}\text { Cervical amputation } \\
(n=77)\end{array}$ & $\begin{array}{l}\text { Vaginal hysterectomy } \\
(n=75)\end{array}$ & & $\begin{array}{l}\text { Cervical amputation } \\
(n=51)\end{array}$ & $\begin{array}{l}\text { Vaginal hysterectomy } \\
(n=48)\end{array}$ & \\
\hline $\mathrm{Aa}$ & $0.4(1.6)$ & $0.8(1.7)$ & 0.160 & $-1.7(1.2)$ & $-1.7(1.2)$ & 0.935 \\
\hline $\mathrm{Ba}$ & $1.7(2.1)$ & $2.0(1.9)$ & 0.299 & $-1.4(1.2)$ & $-1.6(1.3)$ & 0.525 \\
\hline $\mathrm{C}$ & $-1.8(2.6)$ & $0.4(3.4)$ & 0.000 & $-7.0(1.1)$ & $-6.8(2.2)$ & 0.546 \\
\hline GH & $4.5(1.1)$ & $5.0(1.1)$ & 0.006 & $4.0(0.9)$ & $3.6(0.9)$ & 0.027 \\
\hline PB & $3.3(1.0)$ & $3.7(0.9)$ & 0.006 & $3.9(0.9)$ & $3.6(0.8)$ & 0.034 \\
\hline TVL & $9.4(0.9)$ & $9.7(1.2)$ & 0.030 & $8.7(0.9)$ & $8.9(1.2)$ & 0.319 \\
\hline Ap & $-1.2(1.3)$ & $-0.9(1.2)$ & 0.145 & $-2.4(0.9)$ & $-2.5(0.9)$ & 0.427 \\
\hline $\mathrm{Bp}$ & $-1.1(1.3)$ & $-0.7(1.5)$ & 0.053 & $-2.4(1.2)$ & $-2.4(1.0)$ & 0.770 \\
\hline $\mathrm{D}$ & $-5.1(2.0)$ & $-3.8(3.1)$ & 0.002 & $-7.5(1.2)$ & - & - \\
\hline
\end{tabular}

Data are presented as mean (SD)

$P p$ value using an independent samples Student's $t$ test

Table 4 The overall and compartmental stages of the pre- and postoperative pelvic organ prolapse quantification examinations

\begin{tabular}{|c|c|c|c|c|}
\hline & \multicolumn{2}{|l|}{ Preoperative } & \multicolumn{2}{|l|}{ Postoperative 1year } \\
\hline & Cervical amputation $(n=73)$ & Vaginal hysterectomy $(n=72)$ & Cervical amputation $(n=50)$ & Vaginal hysterectomy $(n=48)$ \\
\hline \multicolumn{5}{|c|}{ Overall POP-Q stage } \\
\hline Stage 0 & $0(0)$ & $0(0)$ & $6(12.0)$ & $6(18.8)$ \\
\hline Stage 1 & $0(0)$ & $1(1.4)$ & $14(28.0)$ & $13(27.1)$ \\
\hline Stage 2 & $24(32.9)$ & $19(26.4)$ & $29(58.0)$ & $25(52.1)$ \\
\hline Stage 3 & $48(65.8)$ & $51(70.8)$ & $1(2.0)$ & $1(2.1)$ \\
\hline Stage 4 & $1(1.4)$ & $1(1.4)$ & $0(0)$ & $0(0)$ \\
\hline \multicolumn{5}{|c|}{ Anterior POP-Q stage (Ba) } \\
\hline Stage 0 & $2(2.7)$ & $0(0)$ & $10(20.0)$ & $17(35.4)$ \\
\hline Stage 1 & $2(2.7)$ & $5(6.9)$ & $17(34.0)$ & $8(16.7)$ \\
\hline Stage 2 & $27(37.0)$ & $22(30.6)$ & $22(44.0)$ & $23(47.9)$ \\
\hline Stage 3 & $41(56.2)$ & $44(61.1)$ & $1(2.0)$ & $0(0)$ \\
\hline Stage 4 & $1(1.4)$ & $1(1.4)$ & $0(0)$ & $0(0)$ \\
\hline \multicolumn{5}{|c|}{ Posterior POP-Q stage (Bp) } \\
\hline Stage 0 & $8(11.0)$ & $5(6.9)$ & $30(60.0)$ & $33(68.8)$ \\
\hline Stage 1 & $27(37.0)$ & $14(19.4)$ & $7(14.0)$ & $8(16.7)$ \\
\hline Stage 2 & $33(45.2)$ & $48(66.7)$ & $13(26.0)$ & $7(14.6)$ \\
\hline Stage 3 & $4(5.5)$ & $4(5.6)$ & $0(0)$ & $0(0)$ \\
\hline Stage 4 & $1(1.4)$ & $1(1.4)$ & $0(0)$ & $0(0)$ \\
\hline \multicolumn{5}{|c|}{ Vault/cervix POP-Q stage (C) } \\
\hline Stage 0 & $0(0)$ & $0(0)$ & $23(46.0)$ & $18(37.5)$ \\
\hline Stage 1 & $43(58.9)$ & $24(33.3)$ & $27(54.0)$ & $28(58.3)$ \\
\hline Stage 2 & $20(27.4)$ & $15(20.8)$ & $0(0)$ & $1(2.1)$ \\
\hline Stage 3 & $9(12.3)$ & $32(44.4)$ & $0(0)$ & $1(2.1)$ \\
\hline Stage 4 & $1(1.4)$ & $1(1.4)$ & $0(0)$ & $0(0)$ \\
\hline
\end{tabular}

Data are presented as $n(\%)$ 
Table 5 Preoperative scores and change in scores (preoperative minus postoperative scores) on the incontinence impact questionnaire, urogenital distress inventory, and defaecatory distress inventory

\begin{tabular}{|c|c|c|c|c|c|c|c|}
\hline & \multicolumn{2}{|l|}{ Preoperative } & \multicolumn{2}{|c|}{ Postoperative } & \multicolumn{3}{|c|}{ Change between pre- and postoperative } \\
\hline & $\begin{array}{l}\text { Cervical } \\
\text { amputation }\end{array}$ & $\begin{array}{l}\text { Vaginal } \\
\text { hysterectomy }\end{array}$ & $\begin{array}{l}\text { Cervical } \\
\text { amputation }\end{array}$ & $\begin{array}{l}\text { Vaginal } \\
\text { hysterectomy }\end{array}$ & $\begin{array}{l}\text { Cervical } \\
\text { amputation }\end{array}$ & $\begin{array}{l}\text { Vaginal } \\
\text { hysterectomy }\end{array}$ & $P$ \\
\hline \multicolumn{8}{|l|}{ IIQ } \\
\hline Mobility & $28.7(24.5)$ & $26.6(22.0)$ & $23.7(27.4)$ & $21.6(25.8)$ & $8.3(24.2)$ & $7.6(19.3)$ & 0.900 \\
\hline Physical & $29.0(29.3)$ & $27.3(29.5)$ & $22.6(28.9)$ & $15.3(28.3)$ & $6.4(33.3)$ & $13.8(26.4)$ & 0.301 \\
\hline Social & $17.2(20.4)$ & $13.2(14.1)$ & $14.1(24.5)$ & $9.2(16.0)$ & $7.7(16.3)$ & $6.0(12.4)$ & 0.630 \\
\hline Embarrassment & $18.4(21.3)$ & $14.6(16.9)$ & $14.4(22.4)$ & $11.7(22.4)$ & $6.2(20.2)$ & $6.8(19.8)$ & 0.890 \\
\hline Emotion & $32.6(28.1)$ & $25.9(22.8)$ & $19.8(23.4)$ & $16.2(26.0)$ & $13.7(23.4)$ & $12.8(22.9)$ & 0.868 \\
\hline \multicolumn{8}{|l|}{ UDI } \\
\hline $\begin{array}{l}\text { Overactive } \\
\text { bladder }\end{array}$ & $21.5(20.5)$ & $28.5(23.9)$ & $19.4(19.7)$ & $18.1(22.6)$ & $5.8(19.8)$ & $6.5(15.7)$ & 0.903 \\
\hline Incontinence & $25.5(25.5)$ & $24.0(25.2)$ & $18.7(20.1)$ & $17.2(19.6)$ & $12.6(25.6)$ & $6.4(20.5)$ & 0.249 \\
\hline $\begin{array}{l}\text { Obstructive } \\
\text { micturition }\end{array}$ & $26.0(25.5)$ & $24.0(25.2)$ & $13.4(20.0)$ & $12.9(22.1)$ & $-7.8(17.1)$ & $-10.6(19.9)$ & 0.523 \\
\hline Discomfort/pain & $30.9(24.3)$ & $30.6(30.3)$ & $17.3(20.3)$ & $9.4(13.5)$ & $15.2(22.6)$ & $18.8(28.3)$ & 0.548 \\
\hline Genital prolapse & $51.7(33.4)$ & $54.0(32.7)$ & $7.8(14.7)$ & $10.5(19.1)$ & $43.1(35.0)$ & $41.9(32.5)$ & 0.879 \\
\hline \multicolumn{8}{|l|}{ DDI } \\
\hline Obstipation & $14.2(18.7)$ & $11.9(17.3)$ & $12.1(18.6)$ & $7.8(14.2)$ & $2.9(14.8)$ & $5.0(15.1)$ & 0.555 \\
\hline $\begin{array}{l}\text { Obstructive } \\
\text { defaecation }\end{array}$ & $15.4(19.4)$ & $14.2(16.8)$ & $9.4(13.7)$ & $5.3(10.3)$ & $5.7(14.6)$ & $9.5(15.5)$ & 0.307 \\
\hline Discomfort/pain & $14.2(23.0)$ & $12.2(23.5)$ & $9.0(17.2)$ & $3.1(9.9)$ & $4.4(25.1)$ & $7.0(18.4)$ & 0.621 \\
\hline Incontinence & $2.4(7.7)$ & $6.0(13.7)$ & $5.2(16.8)$ & $5.6(15.5)$ & $-1.0(12.7)$ & $0.9(22.6)$ & 0.669 \\
\hline Flatus & $21.2(27.4)$ & $22.5(25.4)$ & $20.1(26.4)$ & $24.4(26.7)$ & $-4.0(24.2)$ & $-3.7(19.2)$ & 0.959 \\
\hline
\end{tabular}

Data are presented as mean (SD). Note: the change is presented as the mean of the individual score per patient (preoperative score minus postoperative score), consequently, positive values indicate an improvement; whereas, negative values indicate a deterioration in outcome

$P p$ value using an independent $t$ test on the difference between the groups in change of preoperative minus postoperative scores, $I I Q$ incontinence impact questionnaire, $U D I$ urogenital distress inventory, $D D I$ defaecatory distress inventory

known [17]. Most recurrences (60.9\%) appeared asymptomatic with regard to prolapse sensations. There were no differences between the two operations with regards to anterior, middle, or posterior compartment recurrences.

Considering that the hysterectomy cases were more severe preoperatively, it is possible that the modified Manchester is less protective of recurrent or de novo anterior compartment prolapse if we take all stages (including stage 1) into account. We have no explanation for this, because postoperative point $\mathrm{C}$ is similar for both operations, and the technique used for the concomitant anterior colporrhaphy is identical.

As usual, in our hospitals, the postoperative follow-up was performed by the operating surgeon. This possibly introduces some bias in the POP-Q results. The choice between the two operations was done in mutual agreement between the patient and the surgeon, and patient and/or surgeon's preference was not specifically studied. As expected, surgeons choose a vaginal hysterectomy more often in case of more severe descend of the uterus and a cervical amputation more often in case the uterine prolapse is less pronounced. One might expect more surgeons to choose for a cervical amputation in case of significant cervical elongation, which should be reflected in a relatively low point $\mathrm{C}$ with a relatively well-positioned point D. However, this is not reflected in our series. In fact, the opposite held true with the distance D minus $\mathrm{C}$, which was $3.3 \mathrm{~cm}$ in the cervical amputation group and $4.2 \mathrm{~cm}$ in the vaginal hysterectomy group. This difference was not statistically significant. Apparently, only the position of the cervix determined the choice between the two operations. We have no information on whether or not the choice of the patient, and in particular the wish to preserve their uterus, has influenced the type of operation.

The operating time was, as expected, shorter for the cervical amputation group as was the case for the amount of blood loss. However, this might also be a reflection of the more severe prolapse cases in the vaginal hysterectomy group with more stage 3 middle compartment prolapse.

To our surprise, we found a slightly longer hospital stay for the cervical amputation group. This might implicate that there is a selection bias in operation and that women in the cervical amputation group are possibly less fit than the 
vaginal hysterectomy group. Although the co-morbidities for both groups appears to be similar, possibly, the surgeons felt that some patients would tolerate surgery less well and so chose what they thought was a less morbid procedure (cervical amputation), and that would seem to be borne out in the longer hospital stay.

With regard to the difference between pre-and postoperative functional outcome, there were no significant differences on the UDI, DDI, and IIQ results. Our data on the functional outcome with regard to the vaginal hysterectomy group are comparable to a study which studied vaginal hysterectomy with sacrospinous fixation and used the same pre- and postoperative domain scores as outcomes [18].

We found an improvement in the urinary incontinence domain in both groups. The improvement in the cervical amputation group was somewhat bigger, but this did not reach significance. This is in contrast to earlier studies where $22-28 \%$ of the patients developed stress incontinence after the Manchester procedure [19, 20].

It is difficult to compare our results of this modified Manchester procedure with the literature. Most literature on the Manchester operation is written early in the last century. Only one recent study has been found which focuses especially on the complications after a Manchester operation [21].

In conclusion, we found an excellent performance of both procedures with regard to middle compartment recurrence. Both procedures had a high recurrence rate for especially the anterior compartment. One has to realise that the modified Manchester was done in less severe cases and thus possibly performs poorer in this regard than the vaginal hysterectomy. No significant difference in functional outcome was found. The modified Manchester is therefore a viable option in women who wish to preserve their uterus.

\section{Conflicts of interest None.}

Open Access This article is distributed under the terms of the Creative Commons Attribution Noncommercial License which permits any noncommercial use, distribution, and reproduction in any medium, provided the original author(s) and source are credited.

\section{References}

1. Olsen AL, Smith VJ, Bergstrom JO, Colling JC, Clark AL (1997) Epidemiology of surgically managed pelvic organ prolapse and urinary incontinence. Obstet Gynecol 89(4):501-506

2. Costantini E, Mearini L, Bini V, Zucchi A, Mearini E, Porena M (2005) Uterus preservation in surgical correction of urogenital prolapse. Eur Urol 48(4):642-649

3. Diwan A, Rardin CR, Kohli N (2004) Uterine preservation during surgery for uterovaginal prolapse: a review. Int Urogynecol J Pelvic Floor Dysfunct 15(4):286-292
4. Diwan A, Rardin CR, Strohsnitter WC, Weld A, Rosenblatt P, Kohli N (2006) Laparoscopic uterosacral ligament uterine suspension compared with vaginal hysterectomy with vaginal vault suspension for uterovaginal prolapse. Int Urogynecol $\mathrm{J}$ Pelvic Floor Dysfunct 17(1):79-83

5. Dwyer PL, Fatton B (2008) Bilateral extraperitoneal uterosacral suspension: a new approach to correct posthysterectomy vaginal vault prolapse. Int Urogynecol J Pelvic Floor Dysfunct 19(2):283-292

6. Conger GT, Keettel WC (1958) The Manchester-Fothergill operation, its place in gynecology: a review of 960 cases at University Hospitals, Iowa City, Iowa. Am J Obstet Gynecol 76(3):634-640

7. Fothergill W (1915) Anterior colporrhaphy and amputation of the cervix combined as a single operation for use in the treatment of genital prolapse. Am J Surg 26:161

8. Hunter JW (1951) Manchester Fothergill surgery of uterine prolapse. Gynecol Prat 2(5):484-485

9. Vierhout ME (2004) Diagnosis of uterovaginal prolapse. Ned Tijdschr Geneeskd 148(49):2432-2436

10. Uebersax JS, Wyman JF, Shumaker SA, McClish DK, Fantl JA (1995) Short forms to assess life quality and symptom distress for urinary incontinence in women: the incontinence impact questionnaire and the urogenital distress inventory. Continence Program for Women Research Group. Neurourol Urodyn 14(2):131-139

11. Van Brummen HJ, Bruinse HW, Van De PG, Heintz AP, van der Vaart CH (2006) Defecatory symptoms during and after the first pregnancy: prevalences and associated factors. Int Urogynecol J Pelvic Floor Dysfunct 17(3):224-230

12. van der Vaart CH, de Leeuw JR, Roovers JP, Heintz AP (2003) Measuring health-related quality of life in women with urogenital dysfunction: the urogenital distress inventory and incontinence impact questionnaire revisited. Neurourol Urodyn 22(2):97-104

13. Kalogirou D, Antoniou G, Karakitsos P, Kalogirou O (1996) Comparison of surgical and postoperative complications of vaginal hysterectomy and Manchester procedure. Eur J Gynaecol Oncol 17(4):278-280

14. Thomas AG, Brodman ML, Dottino PR, Bodian C, Friedman F Jr, Bogursky E (1995) Manchester procedure vs. vaginal hysterectomy for uterine prolapse. A comparison. J Reprod Med 40(4):299-304

15. Dietz V, Schraffordt Koops, SE, van der Graaf Y., Heintz, AP, van der Vaart CH (2008) One-year follow-up of anatomical outcomes after a sacrospinous hysteropexy and vaginal hysterectomy for uterine descent: a randomized study. Dissertation, Utrecht University, The Netherlands

16. Roovers JP, van der Vaart $\mathrm{CH}$, van der Bom JG, van Leeuwen JH, Scholten PC, Heintz AP (2004) A randomised controlled trial comparing abdominal and vaginal prolapse surgery: effects on urogenital function. BJOG 111(1):50-56

17. Shull BL, Bachofen C, Coates KW, Kuehl TJ (2000) A transvaginal approach to repair of apical and other associated sites of pelvic organ prolapse with uterosacral ligaments. Am J Obstet Gynecol 183(6):1365-1373

18. Dietz V, Huisman M, de Jong JM, Heintz PM, van der Vaart CH (2008) Functional outcome after sacrospinous hysteropexy for uterine descensus. Int Urogynecol J Pelvic Floor Dysfunct 19 (6):747-752

19. Borstad E, Rud T (1989) The risk of developing urinary stressincontinence after vaginal repair in continent women. A clinical and urodynamic follow-up study. Acta Obstet Gynecol Scand 68 (6):545-549

20. Borstad E, Skrede M, Rud T (1991) Failure to predict and attempts to explain urinary stress incontinence following vaginal repair in continent women by using a modified lateral urethrocystography. Acta Obstet Gynecol Scand 70(6):501-506

21. Ayhan A, Esin S, Guven S, Salman C, Ozyuncu O (2006) The Manchester operation for uterine prolapse. Int J Gynaecol Obstet 92(3):228-233 